\title{
Nurse's knowledge, attitude and practice on the initial management of acute poisoning among adult casualties: Study at Kenyatta National Hospital, Kenya
}

\author{
Japheth Rutto*, James Mwaura, Angeline Chepchirchir, Theresa Odero \\ School of Nursing, The University of Nairobi, Nairobi, Kenya \\ Email: ${ }^{* k o l o n g e t @ y a h o o . c o m ~}$
}

Received 13 June 2012; revised 10 July 2012; accepted 18 July 2012

\begin{abstract}
The purpose of this study was to determine nurse's knowledge, attitude and practice on the initial management of acute poisoning among adult casualties seen at Accident and Emergency Department (AED), Kenyatta National Hospital (KNH). The study was cross sectional. Both qualitative and quantitative methods of data collection were employed. The target population were all nurses working at AED, KNH. Purposive sampling was used to select study subjects. Sample size included all Accident and Emergency (A\&E) nurses who met subject's inclusion criteria. Structured questionnaires, observation checklist and interview were used to collect the data. Sixty eight (82\%) of A\&E nurses participated in this study. The study found out that with higher nursing qualification and training on courses related to emergency care, knowledge and skills of $A \& E$ nurses on the initial management of acute poisoning is enhanced. A\&E nurses with lower education level had a higher mean score of positive attitude compared with nurses with higher nursing qualification. Majority 60 (88.2\%) of the $A \& E$ nurses indicated that, they required more training on the initial management of acute poisoning. Study recommends that $A \& E$ nurses should be trained on various types of poisoning including; assessment, clinical presentations and management to include gut decontaminations. In addition, refresher courses should be organised for those already trained. Flowcharts that will enhance easy identification and management of poisoned casualties should be put in place and utilized accordingly.
\end{abstract}

Keywords: Knowledge; Attitude; Practice; Initial Management; Acute Poisoning; Adult Casualties; Accident and Emergency Department; Kenyatta National Hospital (KNH)

${ }^{*}$ Corresponding author.

\section{INTRODUCTION}

Acute poisoning is a substance that causes harmful effect when administered by accident or by design to a living organism [1]. It is a common reason for visits to emergency departments and for hospitalization worldwide and it is a cause of both morbidity and mortality in many parts of the world. Globally it is estimated that poisoning events are responsible for more than one million illnesses annually [2]. According to reference [3,4] majority of acute poisoning cases seen in clinical practice especially in developing countries are as a result of deliberate and accidental ingestion and most of them present themselves at AED for their initial treatment. At $\mathrm{KNH}$, at least two percent $(n=5)$ of patients seen daily are as a result of acute poisoning.

Poisoning affects the patient's condition quickly, and the patient's life can be endangered if there is slight delay in initiating urgent treatment at AED. Decisions on appropriate responses to such casualties have to be appropriate, swift and evidence based [5]. It requires early management decisions to ensure an optimal outcome while at the same time avoiding unnecessary investigation and intervention. Reference [6] suggested that, even though they may not appear acutely ill, all poisoned patients should be treated as if they have a potentially life-threatening intoxication.

Kenya is currently faced with increasing incidences of acute poisoning that range from aflatoxins ingestion, herbicides and pesticides consumption, illicit brews consumption and use of uncertified herbal medicine for treatments. KNH being a major referral hospital within the region has a big responsibility in management of all diverse cases of poisoning. It is therefore fundamental that their medical staffs are well updated on the current management of acute poisoning of any diverse nature.

Accident and Emergency nurses at $\mathrm{KNH}$ are frequently the first health care professionals to come in contact with patients who have ingested poisons. They are often at the 
forefront when it comes to this initial and critical assessment. Their knowledge, skills and positive self esteem are fundamental to their practice and influence the overall patient outcome. They are required to understand the agent ingested, dose ingested, time since ingestion, clinical features, patient factors and geographical location. It is essential that all A\&E nurses are familiar with the clinical priorities in life-threatening situations in order to ensure that problems are identified and treated accordingly.

The Study done by [7] explored the personal experience of poisoned patients in hospitals. They found out that, when patients are transferred to AED they are often ignored, have to wait, experience judgmental comments and painful treatment. Disturbingly, AED is an important access point for these casualties who might be in dire need for emergent life saving interventions.

In the treatment of trauma patients, there is the concept of "golden hour", whereby the first hour represents the best chance to stabilize and treat potentially life threatening injuries before the patient's condition deteriorates. In the management of ingested poisons, a similar concept should be emphasized; after the first hour, the amount of poison removed from the body is much decreased. Medical personnel who care for poisoned patients should keep this concept in mind by considering early decontamination after the overdose, preferably within the first hour [8].

After arriving at the AED, all poisoned patients are triaged as being in a critical or emergency condition, whether they are stable or not. This practice will ensure that the patients can be seen almost immediately for stabilization and consideration for early gut decontamination [8]. The process of assessment starts as soon as the patient arrives at the AED and incorporates the gathering of information regarding the patient's current physiological status along with a history of the present and any previous episodes.

According to the work of [1,9], there are two main elements in the management of poisoned patients. The first is the provision of good supportive care and the second is decontamination or elimination enhancement measures. It begins with a thorough evaluation, recognition that poisoning has occurred, identification of the agent involved, assessment of severity and prediction of toxicity. Supportive care is directed at preventing or limiting the complications of a toxic exposure and is the cornerstone of good management.

Healthcare workers have an individual and collective responsibility to reflect on their own performance and address any deficits in knowledge or skills as well as to evaluate the strengths and weaknesses of their system as a whole [10]. "Chain of Response" should be in place, which should be timely, effective, and seamless. Different professional groups within AED should contribute to different parts of the chain according to the local setting. The most important requirement is that the "overall team" is to posses' competencies that cover assessment, recognition, intervention and communication to ensure help is obtained when needed.

In order to develop and maintain good management skills and practice, reference [11] urge that nursing education must continue to design and develop units of study for casualty nurses. The study should focus on the therapeutic care of poisoned patients at pre- and post-Registration levels as well as in continuing professional education programs. Relevant research findings must be included in the educational programs and specialized teaching units for casualty nurses should be developed.

Attitudes of A\&E nurses towards patients who attempt suicide are particularly important because they are likely to determine the enthusiasm that will be shown in providing help for such patients and hence influence the effectiveness of treatment. Thus, reference [8] suggested that health care professionals should be aware of their attitudes towards this group of patients as part of their professional and therapeutic role.

\subsection{Study Objective}

To determine the nurse's knowledge, attitude and practice on the initial management of acute poisoning among adult casualties seen at AED, KNH.

\subsection{Research Questions}

The study seeks to answer the following questions:

- Do A\&E nurses have adequate and necessary skills, knowledge and positive attitude on the initial assessment and management of poisoned casualties?

- Do social-demographic characteristics of A\&E nurse's affect the initial management of poisoned casualties?

\subsection{Conceptual Framework}

The relationships between the various variable under study are summarized in Figure 1.

\section{METHODOLOGY}

This was a cross sectional study that employed both qualitative and quantitative methods of data collection. The study was conducted at AED, KNH. KNH is a referral hospital in Kenya with a bed capacity of approximately 2000 patients.

The study population were all nurses working at AED, KNH during the time of this study. Purposive sampling was used to select study subjects. Sample size included all the $82 \mathrm{~A} \& \mathrm{E}$ nurses who met the following subject's inclusion criteria; nurses employed and working at $\mathrm{KNH}$ who were either enrolled, registered, BscN or MscN and 


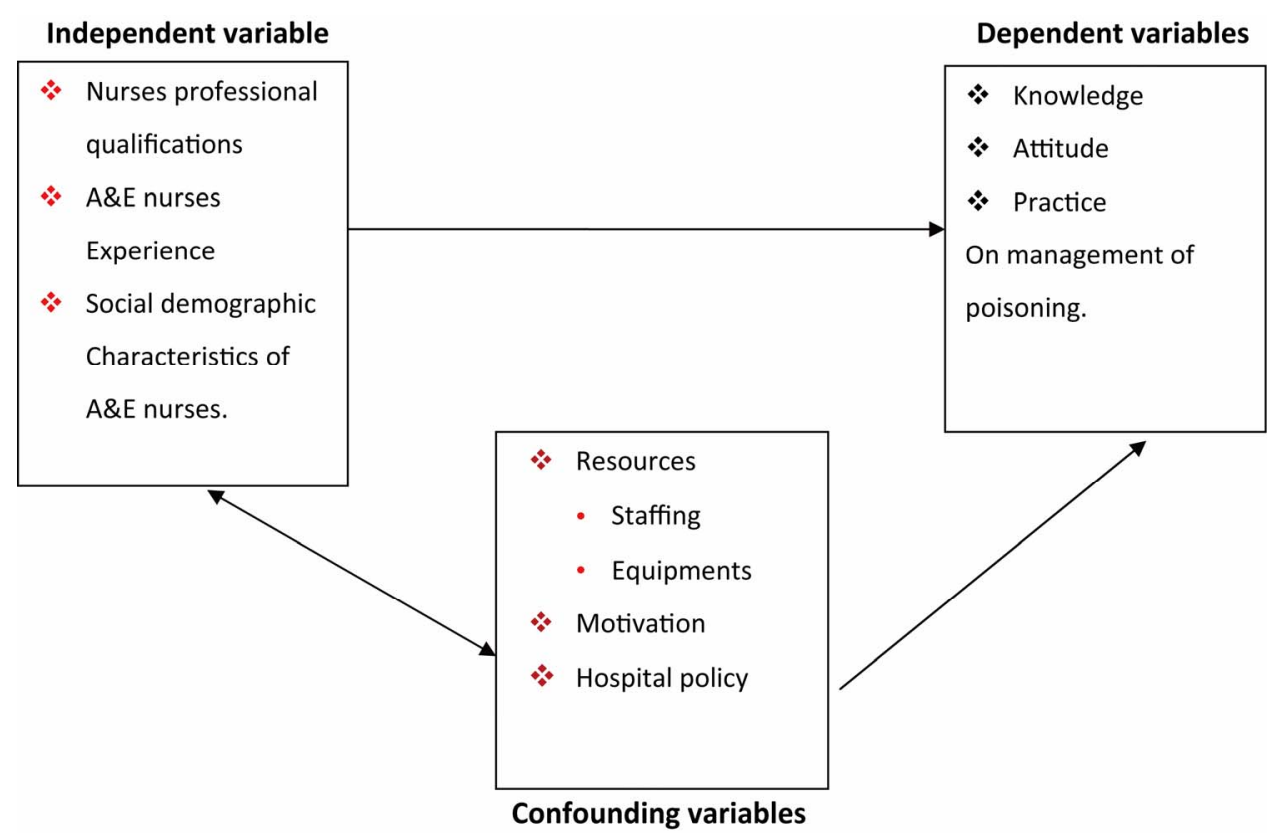

Figure 1. Conceptual framework.

were deployed at AED during the time of the study. Further, they were required to be directly involved in initial patient management and had given a written consent to participate.

Structured questionnaire, observation checklist and interview schedules were used to collect the data. The structured questionnaire consisted of five sections and where; social and demographic data, general knowledge on poisoning, initial management of acute poisoning practices, nurses practices self reporting and nurses attitude rating scale.

Pilot study was done at Mbagathi District Hospital. Fifteen questionnaires were administered to nurses who were deployed at AED to test validity and reliability of the study instrument. Mbagathi District hospital was chosen because it is close proximity to $\mathrm{KNH}$ and shares the same catchment area of poisoned casualties.

Data were cleansed, checked for completeness and entered into Statistical Package of Social Sciences (SPSS) version 16 for analyses. Statistical measures of Central tendency, T-test and ANOVA were used in determining the association between independent and dependent variables. Finally, data were presented as frequency tables, bar graphs and figures. Inferential statistics presented in relation to their level of significance.

Ethical clearance of the proposal was granted by $\mathrm{KNH} /$ University of Nairobi-Ethics and Research Committee. Permission to carry out the study was granted by the Kenya Ministry of Science and Technology and KNH Administration. All A\&E nurses were informed in advance that participation in the study was voluntary and the identities for those who participated were withheld throughout the study. Participants of the study gave a written consent by signing a consent form provided.

\section{RESULTS}

\subsection{Social Demographic Characteristics}

Out of 82 nurses providing nursing care at AED, KNH, 68 of these nurses participated in the study, which was $82 \%$ response rate. There were 41 (60.3\%) female nurses and 27 (39.87\%) male nurses in the study.

The mean age of participants was 36.8 years and standard deviation (SD) of 5.6 with a range of 25 to 53 years. Majority 48 (70.6\%) of participants were aged between 30 to 39 years. Fifteen $(22.1 \%)$ of the nurses were in the age group 40 to 49 years. The five remaining participants were either aged below 30 years or above 50 years. Thirty (44.1\%) of the nurses held diploma nursing qualifications, 23 (33.8\%) had higher diplomas, 10 (14.7\%) had degree and 5 (7.4\%) had certificates in nursing. The average number of years since qualification was 11.9 years (SD 5.7 years).

\subsection{Accident and Emergency Trainings}

At least $95.6 \%$ (65 out of 68) of the nurses had attended one of the A\&E courses. The most commonly attended A\&E course was basic life support training (BLS) attended by 52 (76.5\%) of participants. Forty one (61.2\%)) nurses had been trained in advance cardiac life support (ACLS), 17 (25\%) in accident and emergency nursing. Twenty nine (42.7\%) of nurses had been formally trained in management of acute poisoning after their basic nurs- 
ing qualifications.

\subsection{General Knowledge on Poisoning}

Based on responses to 14 general knowledge items on poisoning, a score (range 0 to 14) was calculated for each nurse. The mean score out of 14 for the entire sample was 8.3 with SD of 2.3 and a range of 2 to 13 . As shown in Table 1, degree nurses had the highest mean score (9.0) on the general knowledge on poisoning while the certificate nurses scored a mean of (8.0) representing the lowest score. Similarly nurses with 5 - 9 years of A\&E experience had higher mean scores than those with less or more than 10 years of experience. Further, nursing trainings and poisoning knowledge was measured basing on 14 general knowledge items. The results indicated that those who had done specific courses related to emergency care scored higher mean scores than their counterparts who had not done the same.

\subsection{Practices among A\&E Nurses on the Initial Management of Acute Poisoning}

Out of the 68 nurses who participated in this study, 13 (19.2\%) gave the correct response to all the ten questions on the initial management of acute poisoning practices. Based on the responses to these 10 items, a score (range 0 - 10) was calculated for each nurse. The mean score for all the nurses in the study was 7.3 (SD 1.5), range 3 to 10. Table 2 summarizes the knowledge of nurses on the initial management of acute poisoning practices according to nursing trainings, formal attendance of courses related to the management of poisoning and length of experience at A\&E.

There was very little variation in nurses' knowledge on the initial management of acute poisoning practices. The mean scores for acute poisoning knowledge practices ranged from 7.2 among certificate nurses to 7.4 for higher diploma and degree nurses $(F=0.09 ; p=0.97)$. Nurses

Table 1. Nursing qualification and the length of experience versus general knowledge on poisoning among A\&E nurse.

\begin{tabular}{ccccc}
\hline & Number (n) & Mean (SD) & Range & ANOVA \\
\hline Nursing qualification & 5 & $8.0(2.4)$ & $2-9$ & $\mathrm{~F}=0.43 ; \mathrm{p}=0.74$ \\
Certificate & 30 & $8.1(2.4)$ & $2-13$ & \\
Diploma & 23 & $8.3(2.4)$ & $3-12$ & \\
Higher diploma & 10 & $9.0(1.7)$ & $7-12$ & \\
$\quad$ Degree & & & & \\
Accident and emergency experience & 40 & $8.0(2.1)$ & $3-12$ & $\mathrm{~F}=2.27 ; \mathrm{p}=0.11$ \\
$\mathbf{0}$ - $\mathbf{4}$ years & 16 & $9.4(2.2)$ & $5-13$ & \\
$\mathbf{5}$ - 9 years & 12 & $8.0(2.8)$ & $2-12$ & \\
$\mathbf{1 0}$ years and above & & &
\end{tabular}

Table 2. A\&E nurses' professional qualification and length of experience versus knowledge on initial management of acute poisoning practices.

\begin{tabular}{ccccc}
\hline & Number (n) & Mean (SD) & Range & ANOVA \\
\hline $\begin{array}{c}\text { Nursing qualification } \\
\text { Certificate }\end{array}$ & 5 & $7.2(1.3)$ & $6-9$ & $\mathrm{~F}=0.29 ; \mathrm{p}=0.97$ \\
Diploma & 30 & $7.3(1.5)$ & $4-10$ & \\
Higher diploma & 23 & $7.4(1.6)$ & $3-10$ & \\
$\quad$ Degree & 10 & $7.4(1.5)$ & $5-9$ & \\
\hline Accident and emergency experience & & & & \\
$\quad \mathbf{0}$ - $\mathbf{4}$ years & 40 & $7.1(1.4)$ & $3-9$ & $\mathrm{~F}=1.10 ; \mathrm{p}=0.35$ \\
$\mathbf{5}$ - 9 years & 16 & $7.7(1.7)$ & $5-10$ & \\
$\mathbf{1 0}$ years and above & 12 & $7.5(1.6)$ & $4-9$ & \\
\hline
\end{tabular}


with 0 to 4 years of A\&E scored 7.1 (SD 1.4), 5 to 9 years scored 7.7 (SD 1.7) while those with experience over 10 years scored 7.5 (SD 1.6).

\subsection{Self Reported Nursing Practices of A\&E Nurses}

Out of the 68 interviewed nurses only 9 (13.2\%) reported that they felt insecure dealing with poisoned casualties because they lack necessary skills and confidence. Thirty two $(64.7 \%)$ of nurses however indicated that, though they were confident in their ability they required the presence of a staff member trained or experienced in poisoning management while responding to poison related emergencies at AED. Majority 56 (82.4\%) of nurses felt that they had professional skills to handle patients with acute poisoning but 60 (88.2\%) still indicated that they required more training on the initial management of acute poisoning. Sixty five (95.6\%) nurses where of the opinion that guidelines on the management of acute poisoning at AED was very necessary. Pertaining the triage of poisoned casualties, 67 (98.5\%) of A\&E nurses felt that it was necessary to develop procedures to im- prove the identification and management of these cases at AED, $\mathrm{KNH}$.

\subsection{A\&E Nurses Perception towards Patients Presenting with Acute Poisoning}

The responses to 12 items on perception of nurses towards patients presenting with acute poisoning were obtained on a five-point Likert scale. On a scale ranging from 12 to 60 with higher scores representing positive attitude, A\&E nurses on this sample scored a mean of 42.1 (SD 6.7) representing a generally positive attitude on management of acute poisoning. The attitude score had a range of 21 to 57. The comparison of attitude scores among nurses according to their nursing professional qualification, A\&E experience, age group, gender and attendance of formal course on the management of acute poisoning is presented in Table 3.

\subsection{Competency of A\&E Nurses on the Management of Acute Poisoning}

The emergency management of fifteen poisoned casualties attended at AED, KNH and conducted by different teams of A\&E nurses were observed. The essence was to observe and document the actual nursing practices during this initial poisoning management among A\&E nurses. The findings of the observations were conducted using structured checklists.

Lastly, nurse in charge of AED, KNH was interviewed and several issues were raised which included; nursing staff shortage, limited resources at AED, few training vacancies on $A \& E$ related courses, few seminars on issues related to acute poisoning management.

\section{DISCUSSION}

The aim of the study was to determine nurses knowledge, attitude and practices on the initial management of acute poisoning and if their social demographic characteristics has any impact on the management.

\subsection{Knowledge}

The mean general knowledge score for nurses according to their professional qualifications, trainings on courses related to emergency care and A\&E experience was measured. Nurses with higher professional qualifications (BscN) had higher mean score compared with the ones with lower professional qualifications (Certificate). Further, those who had done courses or trainings related to emergency care like BLS, ACLS, ATLS, A\&E nursing and CCN had higher mean than those who had not done the same. Similarly, nurses with 5 - 9 years of A\&E experience had a higher mean scores than those with less or more than 10 years of experience.

On measuring the mean knowledge score of A\&E nurses on initial management of poisoning practices, A\&E nurses who had formal training on poisoning, BLS and had specialization in A\&E nursing had higher mean scores than those who had not done. A\&E nurses with formal training on the management of poisoning had a higher mean score (8.5) than those without the training (8.2). A\&E nurses with experience of 5 - 9 years had higher mean score than those with experience below 5 years and above 10 years. The result of the study is consistent with early findings of reference [12] that, after implementation of a teaching package on poisoning, the general knowledge of staff improved while attitudes did not become favorable.

Question that was poorly scored was the alimentary signs and symptoms of acute poisoning during early stages, most nurses could not differentiate this with signs and symptoms affecting other body systems. The area in which nurses displayed the least knowledge was in management of patients who had ingested controlled release preparations with 40 (58.8\%) of nurses recognizing that these patients may benefit from decontamination even after a longer delay.

\subsection{Trainings}

Concept that nurses develop skills and understanding of patient care over time through a sound educational base as well as a multitude of experiences was introduced by reference [13]. It is evident from this study that with any form of nursing training and substantial years of experience 
Table 3. Nursing qualification, length of experience, formal training on poisoning management, age group and gender versus attitude of A\&E nurses towards poisoned casualties.

\begin{tabular}{|c|c|c|c|c|}
\hline & Number (n) & Mean (SD) & Range & ANOVA \\
\hline \multicolumn{5}{|l|}{ Nursing qualification } \\
\hline Certificate & 5 & $44.4(6.0)$ & $36-52$ & $F=1.05 ; p=0.38$ \\
\hline Diploma & 30 & $44.2(7.1)$ & $27-58$ & \\
\hline Higher diploma & 23 & $43.6(4.3)$ & $33-52$ & \\
\hline Degree & 10 & $40.5(7.5)$ & $21-46$ & \\
\hline \multicolumn{5}{|l|}{ A \&E experience } \\
\hline 0 - 4 years & 40 & $41.9(6.8)$ & $21-57$ & $\mathrm{~F}=0.09 ; \mathrm{p}=0.91$ \\
\hline 5 - 9 years & 16 & $42.1(4.8)$ & $35-54$ & \\
\hline 10 years and above & 12 & $42.8(8.5)$ & $27-56$ & \\
\hline \multicolumn{5}{|c|}{$\begin{array}{l}\text { Formal training in management of } \\
\text { acute poisoning }\end{array}$} \\
\hline Yes & 29 & $43.2(4.9)$ & $34-56$ & $\mathrm{~F}=1.31 ; \mathrm{p}=0.26$ \\
\hline No & 39 & $41.3(7.7)$ & $21-57$ & \\
\hline \multicolumn{5}{|l|}{ Age group } \\
\hline 20 - 29 years & 3 & $41(4.6)$ & $36-45$ & $F=0.09 ; p=0.91$ \\
\hline 30 - 39 years & 48 & $42(6.8)$ & $21-57$ & \\
\hline 40 - 49 years & 15 & $43.7(6.1)$ & $36-54$ & \\
\hline 50 years and above & 2 & 35 (11.3) & $27-43$ & \\
\hline \multicolumn{5}{|l|}{ Gender } \\
\hline Male & 27 & $42.07(5.7)$ & $27-56$ & $F=0.001 ; p=0.98$ \\
\hline Female & 41 & $42.12(7.3)$ & $21-57$ & \\
\hline
\end{tabular}

knowledge of nurses on poisoning increased. Twenty nine $\mathbf{( 4 2 . 7 \% )}$ of nurses had been formally trained in management of acute poisoning and 39 (57.3\%) had not received such trainings after their basic nursing qualifications. Study results indicated that 60 (88.2\%) of A\&E nurses needed training on the management of acute poisoning.

\subsection{Attitude}

$\mathrm{KNH}, \mathrm{A} \& \mathrm{E}$ nurses held positive attitudes towards individuals presenting with acute poisoning with a mean of 42.1 (SD 6.7), corresponding with the findings of earlier studies of reference [11,14-17]. However, a third (33.8\%) of nurses reported that they sometimes felt nervous and uncomfortable when caring for these patients especially those with deliberate poisoning. More than half of A\&E nurses agree that, it is frustrating to treat patients who have taken poison and (38.3\%) are for the opinion that they should be treated using "strict" method to curb the practice.

Attitude of A\&E nurses decreased with higher level of education. Certificate nurses had higher mean positive attitude than degree nurses. This was consistent with the findings of Alston and Robinson (1992) cited in [14], who reported that broader educational exposure often prompted nurses from different specialties to question issues around the subject of poisoning. Study results were contrary to findings of [9], that the higher the level of nursing education, the more positive the nurses' attitudes become.

Mean positive attitude of A\&E nurses increased with years of experience, age and poisoning related courses. The findings were consistent with those of earlier studies [15-17], older and more experienced nurses had more supportive attitudes than younger and less experienced nurses.

\subsection{Practice}

It was observed that teams of A\&E nurses managing poisoned casualties sometimes fail to assess, make appropriate diagnosis, plan, intervene and evaluate accordingly. From the study, A\&E nurses sometimes failed to 
check patient respiration rate and rhythm, pulse rate, recognition of distressed patients, taking appropriate patient history and performing evidence based intervention.

Thirty two (64.7\%) of nurses however indicated that, though they were confident in their ability they required the presence of a staff member trained or experienced in poison management while responding to poison related emergencies at AED.

\subsection{Gut Decontamination}

Gastric lavage was the most preferred way of gut decontamination for patients who had taken poison within 1 - 4 hours of ingestion. Sixty (88.2\%) A\&E nurses were aware that the decision to perform Gastro Intestinal (GI) decontamination should be based on the specific poison(s) ingested, time from ingestion to presentation and the presenting and predicted severity of poisoning.

On their actual nursing practices, teams of A\&E nurses were not very keen on noting down the dosage of poison taken as well as presenting signs and symptoms during history taking. It was evident from the results that most A\&E nurses could not differentiate between alimentary signs and symptoms of acute poisoning and those that affect other body systems. The above omissions lead to teams of A\&E nurses doing gastric lavage that had no therapeutic benefit to the patient and contrary to documented guideline that, gastric lavage is of benefit and is acceptable if a patient has ingested a potentially toxic amount of substance and the procedure is performed within one hour of ingestion.

From the study results, 21 (30.9\%) of A\&E nurses concurred that lavage can be performed on patients who have taken kerosene or any other corrosive substance. Sixteen (23.5\%) of A\&E nurses were of the idea that the effectiveness of gastric lavage increased as time from ingestion increases; this demonstrates their ignorance on use, benefits and efficacy of the whole procedure.

\section{CONCLUSION}

The study found out that social demographic characteristics of A\&E nurses such as level of education, gender, age, length of $A \& E$ experience and courses related trainings impacted the initial management of acute poisoning in diverse ways. Higher level of nursing education, $A \& E$ experience, training on courses related to emergency care enhanced the knowledge and practice of A\&E nurses on the initial management of poisoning. $\mathrm{KNH}, \mathrm{A} \& \mathrm{E}$ nurses held positive attitudes towards individuals presenting with acute poisoning. Positive attitude increases with age, A\&E experience and training on courses related to poisoning.

\section{RECOMMENDATION}

It is acknowledged that the study utilized a convenient sample of A\&E nurses of KNH, thus limiting the ability to generalize the findings beyond the current study. A similar study, within Kenya Referral hospitals/Provincial hospitals is recommended.

A\&E nurses should be trained on various types of poisoning including; assessment, clinical presentations and management to include gut decontamination.

Refresher courses should be emphasized in order to maintain the positive changes with regard to the nurses' confidence, knowledge and attitudes.

Flowcharts that will enhance easy identification and management of poisoned casualties should be put in place and utilised accordingly. Such guidelines will improve identifications and management of the casualties.

\section{ACKNOWLEDGEMENTS}

I wish to extend my sincere gratitude to the Ministry of State for Defence for giving me an opportunity to further my studies. Great thanks goes to, The Chief Executive Officer of Kenyatta National Hospital for allowing me to conduct this research at the hospital.

Thanks to all nurses of Kenyatta National Hospital working at Accident and Emergency Department who participated in the study. I know how tight the schedules are, but thank you for finding time towards completing the questionnaires.

Special thanks goes to my research assistant Marilyn Langat who ensured that questionnaires were distributed and returned accordingly. Finally, thanks to Mr. Phillip Ayieko for his assistance in data analysis.

\section{REFERENCES}

[1] Hodgson, E. (2010) A textbook of modern toxicology. 4th Edition, John Wiley \& Sons Publication, New Jersey.

[2] Malangu, N. and Ogunbanjo G.A. (2009) A profile of acute poisoning at selected hospitals in South Africa. South African Journal of Epidemiology and Infection, 24, 14-16.

[3] Fernando, R. (2007) Management of Poisoning. 3rd Edition, The National Poisons Information Centre, National Hospital of Sri Lanka, Colombo.

[4] Greene S.L., Wood, D.M., Gawarammana, I.B., WarrenGash, C., Drakes, N., Jones, A.L. and Dargan, P.I. (2008) Improvement in the management of acutely poisoned patients using an electronic database: Prospective audit and targeted educational intervention. Postgraduate Medical Journal, 84, 603-608. doi:10.1136/pgmj.2007.066043

[5] Senarathna, L., Jon, A., Dhammika D.S., Buckley, N. and Dawson, A. (2008) Personal and professional challenges in the management of deliberate self-poisoning patients in rural Sri Lanka: A qualitative study of rural hospital doctors' experiences and perceptions. British Medical Journal of Public Health, 8, 373.

[6] Oslon, R.K. (2004) Poisoning and drug overdose. 4th Edition, Medical Publishing Division, New York.

[7] McAllister, M., Creedy, D., Moyle, W. and Farrugia, C. (2002) Nurses' attitudes towards clients who self-harm. 
Journal of Advanced Nursing, 40, 578-586. doi:10.1046/j.1365-2648.2002.02412.x

[8] Lau, F.L. (2000) Emergency management of poisoning in Hong Kong. Hong Kong Journal of Emergency Medicine, 6, 288-292.

[9] Burns, M.J. and Schwartzstein, R.M. (1999) Decontamination of poisoned patients.

http://cmbi.bjmu.edu.cn/uptodate/critical\%20care/Intoxic ations/Decontamination\%20of\%20poisoned\%20patients. $\underline{\mathrm{htm}}$

[10] Clegg, T. and Hope K. (1999) The first line of response for people who self-poison: Exploring the options for gut decontamination. Journal of Advanced Nursing, 30, 13601367. doi:10.1046/j.1365-2648.1999.01237.x

[11] Sun, F.-K., Long A. and Boore, J. (2007) The attitudes of casualty nurses in Taiwan to patients who have attempted suicide. Journal of Clinical Nursing, 16, 255-263. doi:10.1111/j.1365-2702.2005.01479.x

[12] Turnbull, G. and Chalde, T. (1997) Effects of education on attitudes to deliberate self-harm. Psychiatric Bulletin,

\section{1, 334-335. doi:10.1192/pb.21.6.334}

[13] Benner, P. (1984) From novice to expert: Excellence and power in clinical nursing practice. Addison-Wesley Publishers, Menlo Park.

[14] Anderson, M. (1997) Nurses' attitude towards suicidal behaviour-A comparative study of Community health nurses and nurses working in an accident and emergency department. Journal of Advanced Nursing, 25, 1283-1291. doi:10.1046/j.1365-2648.1997.19970251283.x

[15] McCann, T., Clark, E., McConachie, S. and Harvey, I. (2006) Accident and emergency nurses' attitudes towards patients who self-harm. Accident and Emergency Nursing, 14, 4-10 doi:10.1016/j.aaen.2005.10.005

[16] McCarthy, L. and Gijbels, H. (2010) An examination of emergency department nurses' attitudes towards deliberates self-harm in an Irish teaching hospital. International Emergency Nursing, 18, 29-35. doi:10.1016/j.ienj.2009.05.005

[17] Mclaughlin C. (1994) Casualty nurses' attitudes to attempted suicide. Journal of Advance Nursing, 20, 1111-1118. 